\title{
Vascular Adverse Events Associated with Sitagliptin Agent in Taiwan: A Drug Evaluation Report
}

\author{
Tzu Chin Rojoice Chou ${ }^{1}$, Chuan Liang Chou ${ }^{2}$, Chun Jen Chang ${ }^{2}$, Chien-Chen Chen ${ }^{3}$ and Yu-Hsuan Yen*3,4 \\ ${ }^{1}$ Department of Applied Statistics Information Science and Graduate School of Education, Ming Chuan University, Taiwan
}

${ }^{2}$ Department of Endocrinology and Metabolism, Taipei Medical University, Taiwan

${ }^{3}$ Department of Pharmacy, Taipei Medical University, Taiwan

${ }^{4}$ School of Pharmacy, Taipei Medical University, Taiwan

Received: February 20, 2018; Published: March 01, 2018

*Corresponding author: Yu-Hsuan Yen, Department of Pharmacy, Wan Fang Hospital, Taipei Medical University School of Pharmacy, Taipei Medical University, No. 111, Hsing Long Road, Section 3, Taipei, Taiwan, Tel: 011-886-2-2930-7930; Email: sandrayen@tmu.edu.tw

\section{Abstract}

Objectives: This three-year, long-term study was intended to evaluate the incidence of diabetic macro vascular events, micro vascular events and hypoglycemic events after combining sitagliptin with ant hyperglycemic agents in patients with type 2 diabetes mellitus.

Methods: This is a retrospective observational study of the medical records of type 2 diabetes mellitus patients aged 20 years and older who had been using sitagliptin, metformin and other concomitant ant hyperglycemic agents for more than 60 days from January 1, 2009 to June 30, 2009. All patient medication data were retrieved from the pharmacy database. The primary outcome was to compare the incidence of events such as ischemic stroke, myocardial infarction, peripheral artery occlusive disease, pulmonary embolism, diabetic retinopathy, diabetic nephropathy and severe hypoglycemia in a sitagliptin-based group and a metformin-based group.

Results: Over a mean of 3.6 years, there was a $68 \%$ reduced risk of all the adverse events studied in the sitagliptin-based group compared to the metformin-based group. The sitagliptin-base group had a reduction in risk for ischemic stroke, diabetic retinopathy, and diabetic nephropathy. The subgroup analysis results showed that ORs of incidence of events in patients younger than age 65 years, female and with $\mathrm{HbA1C}$ less than or equal to $7 \%$ after 3 years were significantly lower in the sitagliptin-base group.

Conclusion: Using sitagliptin agents in the treatment of type 2 diabetes mellitus patients may be associated with a reduction in adverse events of vasculopathy

Keywords: Diabetes Mellitus; Sitagliptin; Dpp-4; Metformin; Macrovascular; Microvascular

Abbreviations: HIS: Hospital Information System; IRB: Institutional Review Board; AHAs: Ant Hyperglycemic Agents; IS: Ischemic Stroke; MI: Myocardial Infarction; PAOD: Peripheral Artery Occlusive Disease; PE: Pulmonary Embolism; OR: Odds Ratios; CI: Confidence Intervals; FPG: Fasting Plasma Glucose; HbA1C: Hemoglobin A1A; GLP-1: Glucagon-Like Peptide 1; DPP-4: Dipeptidyl Peptidase IV

\section{Introduction}

The American Diabetes Association recommends metformin as the preferred medication for type 2 diabetes mellitus unless it is contraindicated. Therefore, when blood glucose or hemoglobin A1C (HbA1C) cannot achieve the treatment target, sulfonylurea's, thiazolidinediones, meglitides or insulin can be added to the regimen [1]. However, these medications have different side effects, including hypoglycemia, weight gain and other effects, and they cannot effectively control islet cell damage or complications of type 2 diabetes mellitus. The new pharmacological mechanism for treating diabetes involves the secretion of incretions, including the stimulation of glucagon-like peptide 1 (GLP-1) and gastric inhibitory polypeptide. GLP-1 is secreted by the L cells of the duodenum and jejunum. The promotion of insulin secretion is affected by serum glucose concentration (glucose dependence), thus it rarely causes the side effect of hypoglycemia [2]. The extra pancreatic effect of GLP-1 allows the inhibition of gastric emptying and reduced intake and it can promote long-term weight loss $[3,4]$.

However, intrinsic GLP-1 is very quickly broken down into nonbioactive metabolites by dipeptidyl peptidase IV (DPP-4). Oral DPP4 inhibitors can increase the concentration of intrinsic GLP-1 by 
two to three times. In 12-24 weeks' short-term follow-up, sitagliptin monotherapy effectively reduced $\mathrm{HbA} 1 \mathrm{C}$ and the adverse effects of hypoglycemic events or weight gain compared to sulfonylurea's or placebo [5-7]. In 4-24 weeks' short-term follow-up, sitagliptin and metformin combination therapy effectively reduced $\mathrm{HbA} 1 \mathrm{C}$ and the adverse effects of hypoglycemic events or weight gain, and it was comparable to concomitant use of a placebo and metformin [8-11]. In 24 weeks' short-term follow-up, sitagliptin and sulfonylurea's combination therapy effectively reduced $\mathrm{HbA} 1 \mathrm{C}$, but the adverse effects of hypoglycemic events or weight gain were greater than with concomitant use of a placebo and sulfonylurea's [12]. An animal study conducted by Goncalves showed that sitagliptin could reduce nitrosative stress, inflammation response and necrosis of retinal cells, providing protection for the retinal vascular cells $[13,14]$.

No related human studies have been conducted on the effect of this drug on retinopathy events. An animal study conducted by Mega showed that sitagliptin improved diabetic metabolic problems, including improving blood glucose and dyslipidemia, and increasing insulin production and sensitivity, indicating that low-dose sitagliptin may improve diabetic nephropathy, glomerulosclerosis and renal microvascular damage [14]. In one year observational studies that were conducted on the effects of this drug on diabetic nephropathy, sitagliptin improved albuminuria in patients with type 2 diabetes mellitus $[15,16]$. Sitagliptin has not found to be nephrotoxic in clinical trials and was well tolerated at adjusted doses in patients with moderate or severe renal insufficiency $[17,18]$. In a meta-analysis conducted by Patil, which included 18 randomized controlled clinical trials, sitagliptin reduced primary cardiac events, and the relative risk (RR) was 0.37 ( $p=0.001)$. The follow-up periods of the included clinical trials ranged from 24 weeks to 116 weeks; they were therefore not long-term observational studies [19]. The studies demonstrated the cardiovascular safety of saxagliptin and alogliptin, but the assumption of cardiovascular protection of DPP-4 inhibitors was not demonstrated $[20,21]$. Long-term observational studies on the effect of sitagliptin on macrovascular and microvascular events are lacking. The purpose of the present study was to observe whether sitagliptin agent is associated with a reduction in diabetic macrovascular events, microvascular events and hypoglycemic events.

\section{Study Results Indicators}

Table 1: Definitions of Study Indicators.

\section{Methods \\ Source of Data}

All patient data for the present study were retrieved from the hospital information system (HIS) of Taipei Medical UniversityMunicipal Wan Fang Hospital. The contents based on the electronic health records included data of the computerized physician order system, hospital admissions, the laboratory information system, the radiological information system, the admission and discharge summary system and the pharmacy checking system. The period of follow-up commenced when the patient appeared in Jan-June 2009 and was followed for more than 3 years, not beginning from their first metformin or sitagliptin prescription. HIS can completely capture all medical tests. Data in HIS were inputted by first-line healthcare personnel, e.g. physician's prescriptions, laboratory data, and image reports. However, the limitation is that all patient data were recorded from HIS in our hospital. In Taiwan, patients see the doctor, draw blood, and pick up medicine all in the one hospital. Therefore, all of the details are in their medical records.

\section{Study Population}

The study protocol was approved by the hospital's institutional review board (IRB). Type 2 diabetes mellitus patients aged 20 years or older who had been using sitagliptin, metformin and other concomitant antihyperglycemic agents (AHAs) in the hospital clinic for more than 60 days from January 1, 2009 to June 30, 2009 were selected from the pharmacy database of the pharmacy checking system. In the same study period, patients with the same criteria were searched for using "metformin." Patients with type 1 diabetes mellitus or unstable heart disease; patients who had ischemic stroke (IS), myocardial infarction (MI), peripheral artery occlusive disease (PAOD), pulmonary embolism (PE), diabetic retinopathy, diabetic nephropathy and severe hypoglycemic events at 3 months or more prior to the study; patients with a diabetes history of less than 3 years; and patients with cancer or AIDS were all excluded. The study groups were

a) a metformin-based group in which patients were receiving metformin and/or other AHAs (excluding sitagliptin), and

b) Asitagliptin-based group in which patients were receiving sitagliptin and/or other AHAs.

\begin{tabular}{|c|c|}
\hline $\begin{array}{c}\text { Study } \\
\text { indicators }\end{array}$ & Definitions \\
\hline $\begin{array}{c}\text { Ischemic stroke } \\
\text { (IS) } \\
\text { events }\end{array}$ & $\begin{array}{c}\text { Diagnoses of ICD-9-CM 433, 434, 436, 437, 438; small area infarct on CT and MRI imaging. } \\
\text { ICD-9-CM description: 433, occlusion and stenosis of basilar artery; 434, cerebral embolism or thrombosis with/without cerebral } \\
\text { infarction; 436, acute, but ill-defined, cerebrovascular disease; 437, cerebral atherosclerosis; 438, late effects of cerebrovascular } \\
\text { disease. }\end{array}$ \\
\hline $\begin{array}{c}\text { Myocardial } \\
\text { infarction } \\
\text { (MI) events }\end{array}$ & $\begin{array}{c}\text { Diagnosis of ICD-9-CM 410; admitted to emergency department or hospitalized due to myocardial infarction or underwent cardiac } \\
\text { catheterization and percutaneous } \\
\text { coronary intervention. }\end{array}$ \\
\hline
\end{tabular}




\begin{tabular}{|c|c|}
\hline $\begin{array}{l}\text { Peripheral } \\
\text { artery } \\
\text { occlusive } \\
\text { disease } \\
\text { (PAOD) events }\end{array}$ & $\begin{array}{l}\text { Diagnoses of ICD-9-CM 440.2, 444.2, 459.2; peripheral artery disease or arteriosclerotic changes to extremities angiography. } \\
\qquad \begin{array}{c}\text { ICD-9-CM description: } 440.2 \text {, atherosclerosis of the extremities; } \\
\text { 444.2, arterial embolism and thrombosis of extremity; } 459.2 \\
\text { compression of vein. }\end{array}\end{array}$ \\
\hline $\begin{array}{l}\text { Pulmonary } \\
\text { embolism } \\
\text { (PE) events }\end{array}$ & $\begin{array}{l}\text { Diagnosis of ICD-9-CM 415.1; obstructive ventilator impairment in pulmonary function tests or pulmonary embolism on CT and MRI } \\
\text { imaging. } \\
\qquad \begin{array}{l}\text { ICD-9-CM description: } 415.1 \text {, pulmonary embolism and } \\
\text { infarction. }\end{array}\end{array}$ \\
\hline $\begin{array}{c}\text { Diabetic } \\
\text { retinopathy } \\
\text { events } \\
\text { Diabetic } \\
\text { nephropathy } \\
\text { events }\end{array}$ & $\begin{array}{l}\text { Diagnosis of ICD-9-CM 362.0. } \\
\text { ICD-9-CM description: 362.0, diabetic retinopathy. } \\
\text { The value of } \mathrm{CrCl} \text { or eGFR calculated by Cockcroft-Gault is } \\
\text { smaller than } 60 \mathrm{~mL} / \mathrm{min} \text { and the value of urinary albumin } \\
\text { concentration (UAC) is greater than the baseline and } 30 \mathrm{mg} / \mathrm{L} \text { after } \\
3 \text { years. }\end{array}$ \\
\hline $\begin{array}{c}\text { Severe } \\
\text { hypoglycemic } \\
\text { events }\end{array}$ & $\begin{array}{l}\text { Diagnosis of ICD-9-CM 251.2; admitted to emergency department or hospitalized. } \\
\text { ICD-9-CM description: } 251.2 \text { hypoglycemia }\end{array}$ \\
\hline
\end{tabular}

Clinical events such as IS, MI, PAOD, PE, diabetic retinopathy, diabetic nephropathy and severe hypoglycemia were described in the patients' medical records. The vasculopathy includes IS, MI, PAOD, PE, diabetic retinopathy, and diabetic nephropathy. The time period of the clinical events was recorded during follow up. Each patient tracking of adverse events exceeded 3 years (Table 1). Subgroup analysis was conducted on the two groups divided by age, that is, younger than 65 years or 65 years and older; the event OR including IS, MI, PAOD, PE, diabetic retinopathy, diabetic nephropathy and severe hypoglycemic events was adjusted by sex, the Charlson co-morbidity index score and HbA1C. Subgroup analysis was conducted on the two groups divided by sex; the event OR was adjusted by age, the Charlson co-morbidity index score and HbA1C. Subgroup analysis of HbA1C was conducted after patients had received the medications for three years; the event OR was adjusted by age, sex, and the Charlson co-morbidity index score.

The achievement of the treatment goal $(\leq 7 \%)$ of HbA1C over a 3-year period was defined as the proportion of patients with $\mathrm{HbA1C}$ $\leq 7 \%$ before enrollment and the proportion of patients with $\mathrm{HbA1C}$ $\leq 7 \%$ after enrollment in the sitagliptin-based group compared to the metformin-based group. The improvement of $\mathrm{HbA} 1 \mathrm{C}>7 \%$ from $\mathrm{HbA} 1 \mathrm{C}$ at the baseline to achieve the treatment $(\leq 7 \%)$ of $\mathrm{HbA} 1 \mathrm{C}$ over a 3-year period was defined. The achievement of the treatment goal $(\leq 100 \mathrm{mg} / \mathrm{dL}$ ) of low-density lipoprotein cholesterol (LDL) over a 3-year period was defined as the proportion of patients with $\mathrm{LDL} \leq 100 \mathrm{mg} / \mathrm{dL}$ before enrollment and the proportion of patients with $\mathrm{LDL} \leq 100 \mathrm{mg} / \mathrm{dL}$ after enrollment in the sitagliptin-based group compared to the metformin-based group. The improvement of LDL > $100 \mathrm{mg} / \mathrm{dL}$ from LDL at the baseline to achieve the treatment $(\leq 100 \mathrm{mg} / \mathrm{dL}$ ) of LDL over a 3 -year period was defined.

\section{Statistical Analysis}

The first set of analyses included the definitions of the study indicators and descriptive statistics comparisons for the demographic and clinical characteristics of the patients in the two groups, and it were analyzed by two sample t- tests, the Chisquare test, and the Hosmer and Lemeshow test. The second set of analyses concerned a comparison of the rates of outcomes during the current use of different diabetes medications. Odds ratios (OR) in logistic regression and 95\% confidence intervals (CI) were used as the study result indicators and in the subgroup analysis. OR and 95\% CIs were adjusted by age, sex, the Charlson co-morbidity index score and $\mathrm{HbA1C}$. The third set of analyses included events analysis and test values analysis. The events analysis involved subgroup analysis by relative odds of adverse events over a 3-year period. The relative events analysis was arranged as follows:

a. Age OR is adjusted for sex, the Charlson co-morbidity index score and $\mathrm{HbA} 1 \mathrm{C}$.

b. Gender OR is adjusted for age, the Charlson co-morbidity index score and $\mathrm{HbA} 1 \mathrm{C}$.

c. HbA1C OR is adjusted for age, sex, and the Charlson comorbidity index score.

The purpose of this events analysis was to identify whether reduced risk effects existed within the subgroups. Applied test values analysis was then carried out to trace the achievement of the treatment goal $(\leq 7 \%)$ of $\mathrm{HbA} 1 \mathrm{C}$, and the achievement of the treatment goal $(\leq 100 \mathrm{mg} / \mathrm{dL})$ of LDL over a 3-year period for the metformin-based group and the Sitagliptin-metformin-based group. The purpose of this test values analysis was to confirm the 
treatment targets in various interest outcomes for the two groups. All statistical analyses were determined by IBM Statistical Package for Social Sciences statistical software version 17 (SPSS, Chicago, Illinois, USA).

\section{Study Results \\ Demographics}

In the whole study population, 905 subjects were type 2 diabetes mellitus patients using metformin or sitagliptin. A total of 134 patients were excluded, including:

a. 50 patients who did not use the medications continuously for more than 60 days.

b. 16 type 2 diabetes mellitus patients aged less than 20 years.

c. 8 patients with unstable heart disease. d. 19 patients who had clinical events including ischemic stroke, myocardial infarction, peripheral artery occlusive disease, pulmonary embolism, diabetic retinopathy, diabetic nephropathy and hypoglycemia three months before enrollment.

e. 21 patients with diabetes history less than 3 years.

f. 20 patients with either cancer or AIDS. There were therefore 771 out of 905 patients included in the study.

(Table 2) shows the patient demographic and clinical data. The Charlson co-morbidity index scores of the sitagliptin-metforminbased group was $1.9 \mathrm{r} 1.00$, which was higher than that of the metformin-based group (1.4 $\mathrm{r}$ 0.83). HbA1C of the sitagliptinmetformin-based group was $7.9 \mathrm{r} 1.34$, which was higher than that of the metformin-based group ( 7.2 r 1.4 ).

Table 2: Demographic and clinical characteristics of patients.

\begin{tabular}{|c|c|c|}
\hline \multirow{2}{*}{ Characteristic } & Sitagliptin-based group N = 206 & \multirow{2}{*}{ Metformin-based group N = 565} \\
\hline & No. (\% or SD) & \\
\hline Age (SD) & $63.7(11.91)$ & $62.2(12.61)$ \\
\hline Sex: Male & $99(48.1)$ & $62.2(12.61)$ \\
\hline Charlson co-morbidity & $1.9(1.00)$ & $1.4(0.83)$ \\
\hline \multicolumn{3}{|c|}{ Index Score (SD)† } \\
\hline $\mathrm{HbA1C}(\mathrm{SD}) \dagger$ & $7.9(1.34)$ & $7.2(1.40)$ \\
\hline \multirow[t]{2}{*}{ LDL (SD) } & $105.9(28.32)$ & $104.3(26.43)$ \\
\hline & available, $n=163$ & available, $n=382$ \\
\hline \multicolumn{3}{|c|}{ Medications } \\
\hline Antihypertension drugs & $139(67.5)$ & $87(68.1)$ \\
\hline Lipid-lowering drugs & $116(56.3)$ & $301(53.3)$ \\
\hline Sulfonylurea & $108(52.4)$ & $261(46.2)$ \\
\hline Thiazolidinedione & $26(12.3)$ & $33(5.8)$ \\
\hline Sitagliptin only & $15(7.2)$ & 188(33.2) \\
\hline \multicolumn{3}{|c|}{ Metformin Only } \\
\hline No. of AHAs & $61(29.6)$ & $209(37.0)$ \\
\hline
\end{tabular}

\section{Events Analysis}

The Hosmer-Lemeshow test was used to test the $\chi 2$ values, which were not significant, and which represented acceptable goodness of fit. During the mean follow-up of 3.6 years (SD: 0.17), there was a $68 \%$ reduced risk of all adverse events studied in the sitagliptin-based group (95\% CI: 0.21 to 0.49 ) compared to the metformin-based group. A sitagliptin-based group had a reduction in risk for IS (OR $=0.49 ; 95 \% \mathrm{CI}: 0.26$ to 0.91$)$, diabetic retinopathy $(\mathrm{OR}=0.32 ; 95 \% \mathrm{CI}: 0.12$ to 0.83$)$, and diabetic nephropathy $(\mathrm{OR}=$ 0.30 ; $95 \%$ CI: 0.18 to 0.52$)$ and a trend of less MI (OR $=0.29 ; 95 \%$ CI: 0.05 to 1.65 ), PAOD (OR $=0.58 ; 95 \%$ CI: 0.22 to 1.54 ), and severe hypoglycemia (OR $=0.29$; $95 \%$ CI: 0.08 to 1.10 ) No OR data for PE, because the incidence of PE was too small to calculate (Table 3 ). The mean years of clinical events occurring was 2.4 (SD: 0.86) for
IS, 2.2 (SD: 1.06) for MI, 2.9 (SD: 0.91) for PAOD, 2.7 (SD: 1.06) for diabetic retinopathy, and 3.1 (SD: 0.94) for diabetic nephropathy. Subgroup analysis was conducted in two groups divided by age, that is, younger than age 65 years or age 65 years and older; the events OR in the group younger than age 65 years as adjusted by sex, Charlson co-morbidity index score and HbA1C was 0.30 (95\% CI, 0.16-0.57), which was statistically and significantly lower than that of the group aged 65 years and older. Subgroup analysis also was conducted in two groups divided by sex; the incidence in females was statistically and significantly lower than that in females. Subgroup analysis of HbA1C was conducted after patients had received the medications for three years; OR of events in patients with HbA1Cwere no difference (Figure 1). In addition, only $71 \%$ of patients had complete LDL tests and data were biased, thus subgroup analysis was not conducted. 
Table 3: Patient numbers, relative odds of adverse events.

\begin{tabular}{|c|c|c|c|c|}
\hline \multirow{2}{*}{ Outcome } & $\begin{array}{c}\text { Sitagliptin-based group } \\
\mathbf{N}=\mathbf{2 0 6}\end{array}$ & $\begin{array}{c}\text { Metformin-based group } \\
\text { N = 565 }\end{array}$ & $\begin{array}{c}\text { ORs for sitagliptin-based } \\
\text { group }\end{array}$ \\
\cline { 2 - 5 } & \multicolumn{3}{|c|}{ No. (\%) } \\
\hline All Events $\dagger$ & $53(25.7)$ & $225(39.8)$ & 0.32 & $0.21-0.49$ \\
\hline IS $\dagger$ & $19(9.2)$ & $80(14.2)$ & 0.49 & $0.26-0.91$ \\
\hline MI & $2(1.0)$ & $15(2.7)$ & 0.29 & $0.05-1.65$ \\
\hline PAOD & $7(3.4)$ & $27(4.8)$ & 0.58 & $0.22-1.54$ \\
\hline PE & $0(0.0)$ & $4(0.7)$ & N/A & N/A \\
\hline Retinopathy $\dagger$ & $7(3.4)$ & $41(7.3)$ & 0.32 & $0.12-0.83$ \\
\hline Nephropathy $\dagger$ & $32(15.5)$ & $121(21.4)$ & 0.30 & $0.18-0.52$ \\
\hline Hypoglycemia & $4(1.9)$ & $13(2.3)$ & 0.29 & $0.08-1.10$ \\
\hline
\end{tabular}

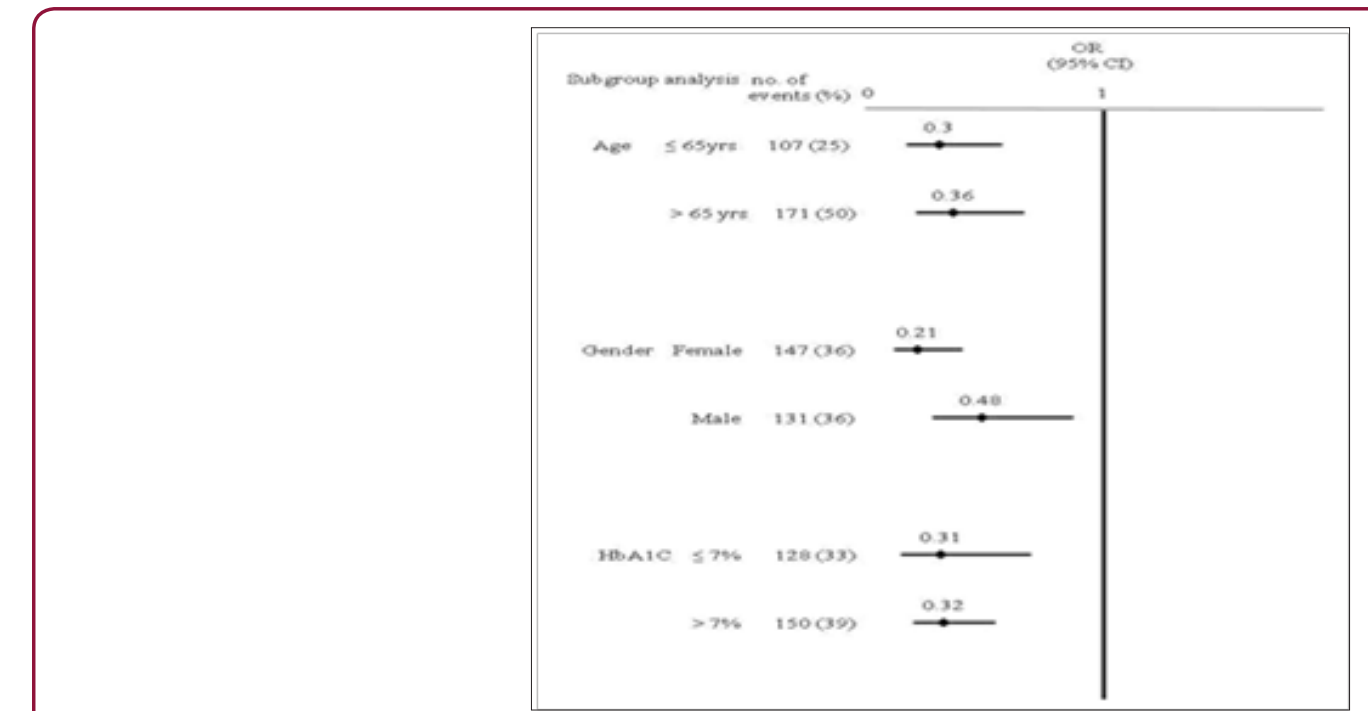

Figure 1: Subgroup analysis by relative odds of adverse events over a 3-year period. Age OR is adjusted for sex, Charlson co-morbidity index score and $\mathrm{HbA1C}$. Gender OR is adjusted for age, Charlson co-morbidity index score and $\mathrm{HbA1C}$. HbA1C OR is adjusted for age, sex, and Charlson co-morbidity index score. OR, odds ratio.

\section{Test values Analysis}

The proportions of patients in the sitagliptin-based group with $\mathrm{HbA} 1 \mathrm{C} \leq 7 \%$ were $29.2 \%$; after 3 years, the proportions of patients achieving treatment targets significantly increased to $35.6 \%$ (Figure 2). For HbA1C > 7\% at the baseline, after 3 years, among the proportions of patients achieving treatment targets $\mathrm{HbA} 1 \mathrm{C} \leq 7 \%$, the improvement rates of $\mathrm{HbA} 1 \mathrm{C}$ in the metforminbased group were $12.5 \%$; the improvement rates of $\mathrm{HbA} 1 \mathrm{C}$ in the sitagliptin-based group were $14.1 \%$, which was higher than in the metformin-based group (Figure 3). Type 2 diabetes mellitus is a progressive disease characterized by the worsening of multiple abnormalities and loss of glycemic control over time. These patients have a $64 \%$ chance of using antihypertensive agents and a $51 \%$ chance of using lipid-lowering agents. The patients whose condition of HbA1C worsened were observed in the metforminbased group. There were more over 65-year-old patients and more using sulfonylurea agents in the metformin-based group. Elderly Patients with diabetes, or diabetes combined with sulfonylurea agents were a group with difficult control of long-term blood sugar (Table 4). There were more missing data in LDL after enrollment.

\section{Discussion}

DPP-4 inhibitors can reduce HbA1C or fasting plasma glucose (FPG). The side effects are limited, weight gain is slowed down and it is only taken once daily [5-12]. Long-term use of some AHAs will reduce the function of pancreatic E cells and result in insulin resistance. An animal study conducted by Farilla showed that GLP-1 reduced the apoptotic enzyme caspase 3 , improved the morphology of E cells, improved the function of E cells and reduced $E$ cell death [22]. DPP-4 inhibitors can increase the physiological activity of GLP1 . Thus, theoretically, it can reduce insulin resistance. Blood glucose control, blood pressure and lipids are closely related. Studies have shown that DPP-4 inhibitors can reduce systolic blood pressure and improve triglyceride levels [23-26]. The present study showed that sitagliptin continuously reduced HbA1C (Figure 2,3) and associated with diabetic metabolism. An animal study conducted by Darsalia showed that linagliptin-mediated efficacy affects GLP-1 due to DPP- 
4 inhibition, and gives neuroprotection, resulting in preventing stroke in diabetic mice [27].

The present study confirmed that the DPP-4 inhibitor sitagliptin associated with $\mathrm{HbA1C}$, affected lipid metabolism and reduced cerebrovascular events in the long-term (Figures 2 \& 3) and (Table 3). However, some AHAs such as rosiglitazone may increase cardiovascular events [28]. Previously, a meta-analysis investigated obstructive cardiovascular events and showed that the incidence of events in the sitagliptin population was 0.6 per 100 Table 4: The Getting Worse of HbA1C of Treatment Over a 3-year Period.

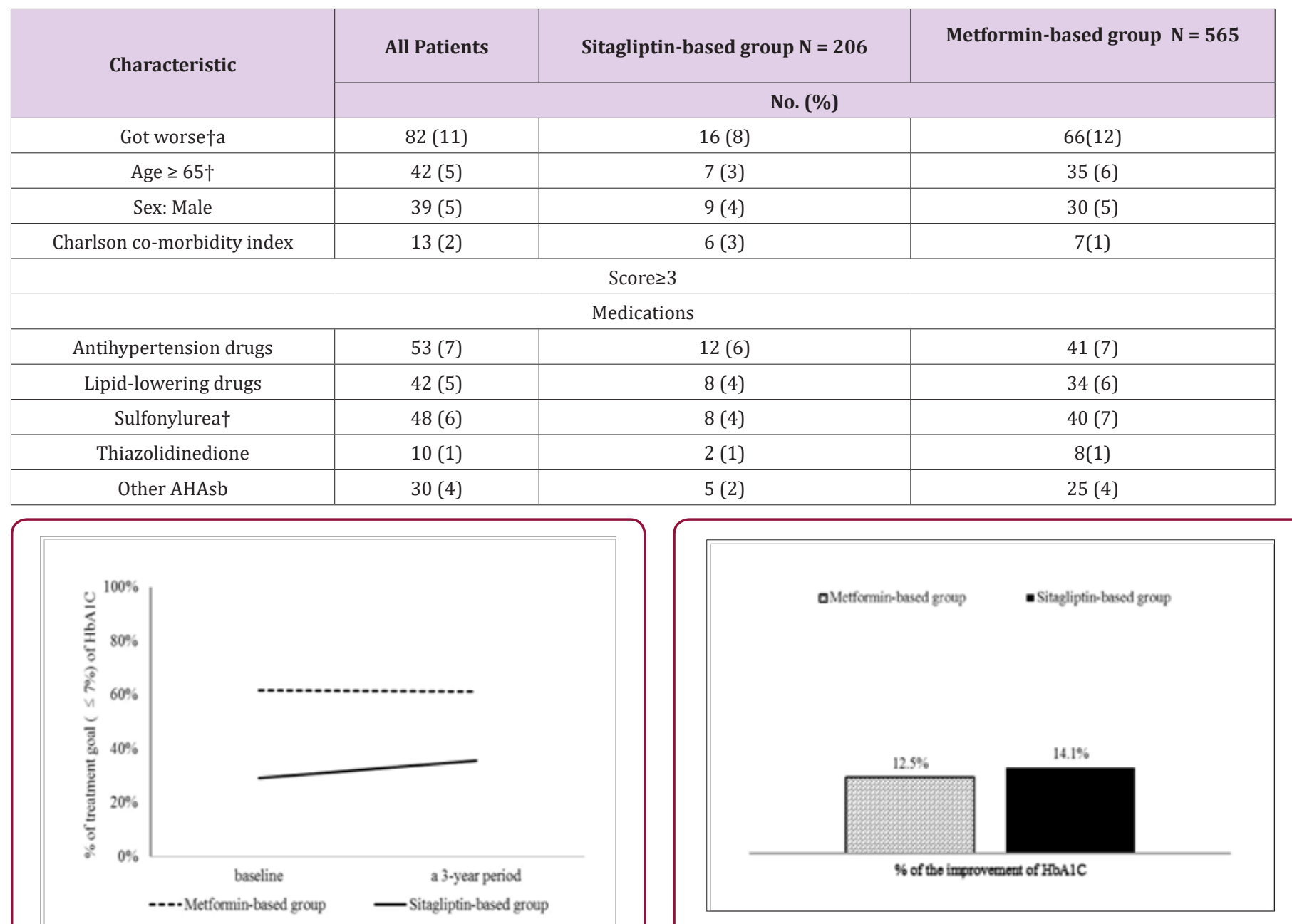

Figure 2: The achievement of treatment goal $(\leq 7 \%)$ of $\mathrm{HbA1C}$ over a 3-year period. HbA1C, hemoglobin A1C.

The present study is a retrospective study with varied disease severity, which is close to the real situation. Cardiovascular events were defined as myocardial infarction or requiring cardiac catheterization or percutaneous coronary intervention. An animal study showed that DPP-4 improved perfusion in peripheral arteries and thus improved PAOD [30]. Our study showed that a sitagliptinbased group had a trend to reduce the incidence of PAOD (Table 3). An animal study of DPP-4 showed that pulmonary vascoactive intestinal peptides improved, which thus improved lung ischemiareperfusion injury [31]. DPP-4 can reduce nitrosative stress, improve retinal inflammatory response, and provide vascular protection of patients per year, compared to the incidence in the non-exposed population, which was 0.9 per 100 patients per year. The incidence of cardiovascular events in sitagliptin/non-exposed was 0.68 (95\% CI: 0.41, 1.12) [29]. No statistically significant differences have been shown in the one-year to two-year short-term study of cardiovascular infarction and stroke events in the studies. Analysis determined that the included patients had histories of severe heart disease, longer diabetes disease duration and older age, and they were easily affected by many factors $[20,21]$.
Figure 3: The improvement of $\mathrm{HbA} 1 \mathrm{C}$ from $\mathrm{HbA} 1 \mathrm{C}>7 \%$ in baseline to achieve the treatment goal $(\leq 7 \%)$ of $\mathrm{HbA} 1 \mathrm{C}$ over a 3-year period. $\mathrm{HbA1C}$, hemoglobin A1C. retinal cells [13]. It also improves diabetic metabolism and diabetic vascular damage, resulting in improved diabetic nephropathy [14]. As shown in (Table 3). Present study also showed that sitagliptin significantly reduced the incidence of diabetic retinopathy and diabetic nephropathy $(\mathrm{p}<0.05)$. The present study had 17 cases of severe hypoglycemic events, in which 12 cases used insulin and 5 cases used sulfonylurea. Thus, the occurrence of hypoglycemia was related to the use of insulin or sulfonylurea. This outcome is identical to the conclusion of the study conducted by WilliamsHerman [32]. 
In the previous ten years, the number of American diabetes patients has increased by $165 \%$; patients aged 75 years or older have increased by $336 \%$. Each year, the number of diabetes patients admitted to hospital is 4 times more than the admission of patients overall. Among these admitted diabetes patients, $87.4 \%$ are admitted for macrovascular events [33]. Atherosclerosis is the major cause of cerebrovascular disease, coronary heart disease and peripheral arterial disease. Long-term high blood glucose inhibits the formation of nitric oxide and increases oxidative stress. Insulin resistance results in the formation of free fatty acids, and also inhibits the formation of nitric oxide and increases oxidative stress. The elderly population is the high risk population for atherosclerosis [34]. A study conducted by Pearte investigated fatal and nonfatal coronary artery disease events; the OR of elderly patients aged 65 years and older was 1.21; no differences were found for sex or race [35]. The present study showed that older age and poor blood glucose control resulted in higher incidence of vasculopathy (Figure 1).

Additionally, the incidence in females was lower than in males. High blood glucose results in functional damage of mitochondria and the endoplasmic reticulum and leads to the accumulation of reactive oxygen species, thus damaging the vessels [36]. This results in macrovascular and microvascular events. The present study showed that $\mathrm{HbA1C}$ controlled to less than $7 \%$ significantly reduced the incidence of both macrovascular and Microvascular events (Figures $2 \& 3$ ). Age was shown to be the factor increasing adverse events (Figure 1). However, the limitation of this retrospective study was that the disease severity and laboratory diagnostic values in the demographics of the two groups could not be controlled. In the experimental sitagliptin-based group, the patients had a higher disease severity and HbA1C, so the incidence of adverse events would be expected to be higher.

The possible reason for this difference may be that sitagliptin was a new drug in our hospital in 2009 and most physicians prescribed it for more severe diabetic patients. In our evaluation of the data in this three-year observational study, other demographics were similar. The study results showed that the sitagliptin-based group had lower risks (Table 3). It was further inferred that the DPP-4 inhibitor sitagliptin could delay disease progression of type 2 diabetes mellitus. However, in evaluating the deviations of differences between the two groups, it is possible that we might underestimate the risks of the control group. Our long-term observational study of sitagliptin with (or without) metformin for treatment of type 2 diabetes mellitus patients indicated that it may be associated with a reduction in adverse events of vasculopathy (Table 3). However, we also suggest that further randomized trials should be conducted in the future to confirm the safety and efficacy of long-term use of DPP-4 inhibitors.

\section{Conclusion}

Sitagliptin-based agents for treating type 2 diabetes mellitus patients were associated with a reduction in adverse events of diabetes-related vasculopathy. The incidence of vasculopathy was significantly higher in males over age 65 years and with $\mathrm{HbA1C}$ greater than $7 \%$.

\section{References}

1. Nathan DM, Buse JB, Davidson MB, Heine RJ, Holman RR, et al. (2006) Management of hyperglycemia in type 2 diabetes: A consensus algorithm for the initiation and adjustment of therapy: A consensus statement from the American Diabetes Association and the European Association for the Study of Diabetes. Diabetes Care 29(8): 1963-1972.

2. Baggio LL, and Drucker DJ (2007) Biology of incretins: GLP-1 and GIP. Gastroenterology 132(6): 2131 - 2157.

3. Edholm T, Degerblad M, Gryback P, Hilsted L, Holst JJ, et al. (2010) Differential incretin effects of GIP and GLP-1 on gastric emptying, appetite, and insulin-glucose homeostasis. Neurogastroenterol Motil 22(11): 1191 - 2000, e315.

4. Nicolaus M, Brodl J, Linke R, Woerle HJ, Goke B, and Schirra J (2011) Endogenous GLP-1 regulates postprandial glycemia in humans: relative contributions of insulin, glucagon, and gastric emptying. J Clin Endocrinol Metab 96(1): 229-236.

5. Scott R, Wu M, Sanchez M, Stein P (2007) Efficacy and tolerability of the dipeptidyl peptidase-4 inhibitor sitagliptin as monotherapy over 12 weeks in patients with type 2 diabetes. Int J Clin Pract 61(1): 171-180.

6. Raz I, Hanefeld M, Xu L, Caria C, Williams Herman D, et al. (2006) Sitagliptin Study 023 Group. Efficacy and safety of the dipeptidyl peptidase- 4 inhibitor sitagliptin as monotherapy in patients with type 2 diabetes mellitus. Diabetologia 49(11): 2564-2571.

7. Aschner P, Kipnes MS, Lunceford JK, Sanchez M, Mickel C, et al. (2006) Sitagliptin Study 021 Group. Effect of the dipeptidyl peptidase-4 inhibitor sitagliptin as monotherapy on glycemic control in patients with type 2 diabetes. Diabetes Care 29(12): 2632 - 2637.

8. Brazg R, Xu L, Dalla Man C, Cobelli C, Thomas K, et al. (2007) Effect of adding sitagliptin, a dipeptidyl peptidase- 4 inhibitor, to metformin on 24-h glycaemic control and beta-cell function in patients with type 2 diabetes. Diabetes Obes Metab 9(2): 186-193.

9. Goldstein BJ, Feinglos MN, Lunceford JK, Johnson J, Williams Herman DE (2007) Sitagliptin 036 Study Group. Effect of initial combination therapy with sitagliptin, a dipeptidyl peptidase- 4 inhibitor, and metformin on glycemic control in patients with type 2 diabetes. Diabetes Care 30(8): 1979-1987.

10. Charbonnel B, Karasik A, Liu J, Wu M, Meininger G (2006) Sitagliptin Study 020 Group. Efficacy and safety of the dipeptidyl peptidase-4 inhibitor sitagliptin added to ongoing metformin therapy in patients with type 2 diabetes inadequately controlled with metformin alone. Diabetes Care 29(12): 2638-2643.

11. Nauck M, Meininger G, Sheng D, Terranella L, Stein PP (2007) Sitagliptin Study 024 Group. Efficacy and safety of the dipeptidyl peptidase-4 inhibitor, sitagliptin, compared with the sulfonylurea, glipizide, in patients with type 2 diabetes inadequately controlled on metformin alone: A randomized, double-blind, non-inferiority trial. Diabetes Obes Metab 9(2): 194 - 205.

12. Hermansen K, Kipnes M, Luo E, Fanurik D, Khatami H, et al. (2007) Sitagliptin Study 035 Group. Efficacy and safety of the dipeptidyl peptidase-4 inhibitor, sitagliptin, in patients with type 2 diabetes mellitus inadequately controlled on glimepiride alone or on glimepiride and metformin. Diabetes Obes Metab 9(5): 733-745.

13. Gonçalves A1, Leal E, Paiva A, Teixeira Lemos E, Teixeira F, et al. (2012) Protective effects of the dipeptidyl peptidase IV inhibitor sitagliptin in the blood-retinal barrier in a type 2 diabetes animal model. Diabetes Obes Metab 14(5): 454-463.

14. Mega C, de Lemos ET, Vala H, Fernandes R, Oliveira J, et al. (2011) Diabetic nephropathy amelioration by a low-dose sitagliptin in an animal model of type 2 diabetes (Zucker diabetic fatty rat). Exp Diabetes Res 2011: 162092.

15. Hattori S (2011) Sitagliptin reduces albuminuria in patients with type 2 diabetes. Endocr J 58(1): 69-73. 
16. Mori H, Okada Y, Arao T, Tanaka Y (2014) Sitagliptin improves albuminuria in patients with type 2 diabetes mellitus. J Diabetes Invest $5: 313-319$.

17. Chan JC, Scott R, Arjona Ferreira JC, Sheng D, Gonzalez E, et al. (2005) Safety and efficacy of sitagliptin in patients with type 2 diabetes and chronic renal insufficiency. Diabetes Obes Metab 10(7): 545-555.

18. Arjona Ferreira JC, Marre M, Barzilai N, Guo H, Golm GT, et al. (2013) Efficacy, and safety of sitagliptin versus glipizide in patients with type 2 diabetes and moderate-to-severe chronic renal insufficiency. Diabetes Care 36(5): 1067-1073.

19. Patil HR, Al Badarin FJ, Al Shami HA, Bhatti SK, Lavie CJ, et al. (2012) Metaanalysis of effect of dipeptidyl peptidase-4 inhibitors on cardiovascular risk in type 2 diabetes mellitus. Am J Cardiol 110(6): 826-833.

20. Scirica BM, Bhatt DL, Braunwald E, Steg PG, Davidson J, et al. (2013) Saxagliptin and cardiovascular outcomes in patients with type 2 diabetes mellitus. N Engl J Med 369(14): 1317-1326.

21. White WB, Cannon CP, and Heller SR (2013) Alogliptin after acute coronary syndrome in patients with type 2 diabetes. N Engl J Med 369: 1327-1335.

22. Farilla L, Bulotta A, Hirshberg B (2003) Glucagon-Like Peptide 1 inhibits cell apoptosis and improves glucose responsiveness of freshly isolated human islets. Endocrinology 144(12): 5149-5158.

23. DeFronzo RA, Okerson T, Viswanathan P (2008) Effects of exenatide versus sitagliptin on postprandial glucose, insulin and glucagon secretion, gastric emptying, and caloric intake: a randomized, cross-over study. Curr Med Res Opin 24(10): 2943-2952.

24. Pratley RE, Nauck M, Bailey T (2010) Liraglutide versus sitagliptin for patients with type 2 diabetes who did not have adequate glycaemic control with metformin: a 26-week, randomised, parallel-group, openlabel trial. Lancet 375(9724): 1447-1456.

25. Moretto TJ, Milton DR, Ridge TD (2008) Efficacy and tolerability of exenatide monotherapy over 24 weeks in antidiabetic drug-naive patients with type 2 diabetes: a randomized, double-blind, placebocontrolled, parallel-group study. Clin Ther 30(8): 1448-1460.

26. Garber A, Henry R, Ratner R (2009) Liraglutide versus glimepiride monotherapy for type 2 diabetes (LEAD-3 Mono): a randomised, 52-week, phase III, double-blind, parallel-treatment trial. Lancet 373(9662): 473-481

27. Darsalia V, Ostsater H, Olverling A (2013) The DPP-4 inhibitor linagliptin counteracts stroke in the normal and diabetic mouse brain: a comparison with glimepiride. Diabetes 62(4): 1289-1296.

28. Nissen SE, Wolski K (2007) Effect of rosiglitazone on the risk of myocardial infarction and death from cardiovascular causes. N Engl J Med 356: 2457-2471.

29. Engel SS, Golm GT, Shapiro D, Davies MJ (2013) Cardiovascular safety of sitagliptin in patients with type 2 diabetes mellitus: a pooled analysis. Cardiovascular Diabetology 12(1): 3.

30. Segers VFM, Revin V, Wu W (2011) Protease-resistant stromal cellderived factor- 1 for the treatment of experimental peripheral artery disease. Circulation 123 (12): 1306-1315.

31. Jungraithmayr W, De Meester I, Matheeussen V (2012) CD26/DPP4 inhibition recruits regenerative stem cells via stromal cell-derived factor-1 and beneficially influences ischaemia-reperfusion injury in mouse lung transplantation. Eur J Cardiothorac Surg 41(5): 1166-1173.

32. Williams-Herman D, Engel SS, Round E (2010) Safety and tolerability of sitagliptin in clinical studies: a pooled analysis of data from 10,246 patients with type 2 diabetes. BMC Endocr disord 10(7): 1-21.

33. Gambert SR, Pinkstaff S (2006) Emerging epidemic: diabetes in older adults: demography, economic impact, and pathophysiology. Diabetes Spectrum 19(4): 221-228.

34. Gunasekaran U, Fowler MJ (2010) Macrovascular disease in elderly patients with diabetes. Clin Geriatr 18(9): 30-34.

35. Pearte CA, Furberg CD, O’Meara ES (2006) Characteristics and baseline clinical predictors of future fatal versus nonfatal coronary heart disease events in older adults: The Cardiovascular Health Study. Circulation 113(18): 2177-2185

36. Fiorentino TV, Prioletta A, Zuo P (2013) Hyperglycemia-induced oxidative stress and its role in diabetes mellitus related cardiovascular diseases. Curr Pharm Des 19(32): 5695 - 5703.
(C) This work is licensed under Creative Submission Link: http://biomedres.us/submit-manuscript.php

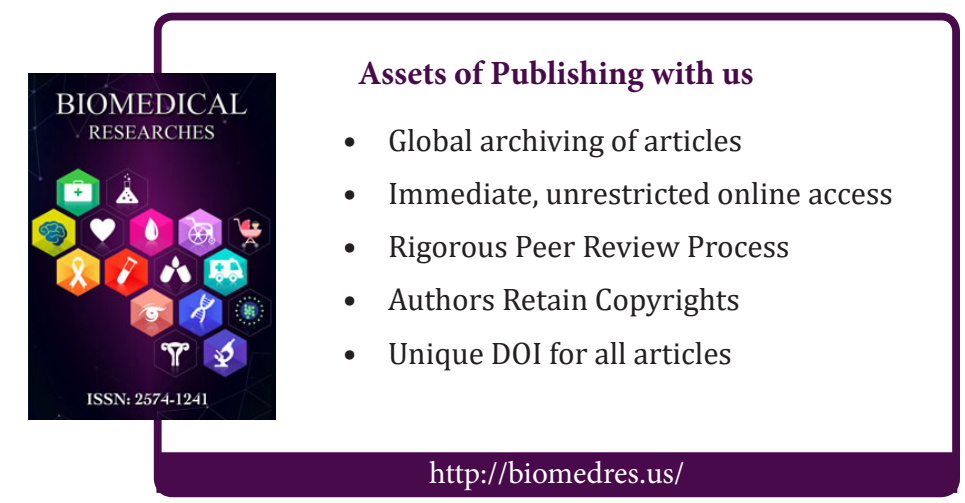

